\title{
Italy's Path to Very Low Fertility: The Adequacy of Economic and Second Demographic Transition Theories
}

\section{Le cheminement de l'Italie vers les très basses fécondités: Adéquation des théories économique et de seconde transition démographique}

\author{
David I. Kertzer · Michael J. White • \\ Laura Bernardi · Giuseppe Gabrielli
}

Received: 24 May 2007 / Accepted: 29 January 2008/Published online: 27 March 2008

(C) Springer Science+Business Media B.V. 2008

\begin{abstract}
The deep drop of the fertility rate in Italy to among the lowest in the world challenges contemporary theories of childbearing and family building. Among high-income countries, Italy was presumed to have characteristics of family values and female labor force participation that would favor higher fertility than its European neighbors to the north. We test competing economic and cultural explanations, drawing on new nationally representative, longitudinal data to examine first union, first birth, and second birth. Our event history analysis finds some support for economic determinants of family formation and fertility, but the clear importance of regional differences and of secularization suggests that such an explanation is at best incomplete and that cultural and ideational factors must be considered.
\end{abstract}

Keywords Fertility - Union formation - Italy · Demographic theories · Event history analysis · Social change - Geographical differences

Résumé La fécondité a baissé de façon très marquée en Italie, pour atteindre à présent un des niveaux les plus bas du monde, ce qui représente un défi pour les théories contemporaines de la procréation et de la formation des familles. Parmi les

D. I. Kertzer · M. J. White $(\bowtie)$

Population Studies and Training Center, Brown University, 68 Waterman Street, Providence, RI 02912, USA

e-mail: Michael_White@brown.edu

L. Bernardi

Max Planck Institute for Demographic Research, Konrad-Zuse-Strasse 1, 18057 Rostock, Germany

e-mail: bernardi@demogr.mpg.de

G. Gabrielli

Department for the Study of Mediterranean Cultures, University of Bari, Bari, Italy 
pays à revenus élevés, l'Italie disposait de caractéristiques en matière de valeurs familiales et de participation des femmes au marché du travail qui auraient dû lui permettre de bénéficier d'une fécondité plus élevée que celle des pays voisins vers le Nord. Nous testons des hypothèses économiques et culturelles, à l'aide de nouvelles données longitudinales représentatives à l'échelle nationale, nous permettant d'examiner la première union et les première et seconde naissances. L'analyse biographique que nous avons menée fournit des éléments en faveur des déterminants économiques de la formation des familles et de la fécondité, mais l'importance des différences régionales et de la sécularisation suggère que ce type d'explication est au mieux incomplet, et que des facteurs culturels et normatifs doivent être pris en considération.

Mots-clés Fécondité · Formation des unions - Italie - Théories démographiques . Analyse biographique $\cdot$ Changement social $\cdot$ Différences géographiques

\section{Introduction}

The geographic distribution of very low fertility among the countries of the world, especially within Europe, remains a puzzle. Rapidly falling fertility in these Western countries, many scholars argued, could be explained by the massive entry of women into the extra-domestic labor force. Others, doubting that a purely economic approach would prove adequate, identified basic culture change as generating very low fertility. Along these lines, Second Demographic Transition (SDT) theorists pointed to a shift in cultural values linked both to a move away from familism toward self-realization and a shift from religious attachments toward secularism.

The fact that by the early 1990s Italy and Spain emerged as the countries with the lowest fertility proved a major surprise, if not an embarrassment. In the European context, both countries showed unusually low rates of female labor force participation (FLFP) and relatively strong family bonds and religious institutions. As Chesnais (1998, p. 91) pointed out, "No official population forecast, either national or international, had anticipated a total fertility rate of 1.2 for any country, [much] less for Mediterranean countries, which are still commonly viewed as "laggards" and ... family-oriented. This outcome is probably the biggest surprise of European demographics at the end of the present century." The longstanding fertility differential between Northern and Southern Europe was unexpectedly reversed. Countries viewed as traditional, Catholic, and family-oriented inexplicably had markedly lower fertility than those that were Protestant, more secular, and had weaker family ties (Chesnais 1996, p. 729).

In this article we provide a detailed empirical analysis of the Italian case to shed light on the adequacy of current demographic theorizing on very low fertility. We begin by introducing some major threads in the arguments and offer relevant background on Italy. We then introduce our data and present a series of event history models with longitudinal microdata. We conclude by considering the theoretical lessons of the Italian case. 
To date, economic theories of various kinds have dominated the theoretical debate on very low fertility. Following Becker (1976) and other neoclassical economists (Mincer 1963), much work has focused on increased female autonomy, the movement of more women into the labor force, and calculations of the direct and indirect costs of childbearing to the family economy. At a more macro-level, Easterlin (1976) and colleagues (Easterlin and Cummins 1991) have advanced a theory of relative economic deprivation, linking fertility decisions to economic opportunities related to relative cohort sizes and to judgments based on expected levels of economic well-being linked to demographic and economic cycles. As noted by Macunovich (1997), neither theory seemed to be born out by the course of fertility in the world's wealthier countries in recent years.

The economic feature that has most attracted theorists' attention has been increasing levels of FLFP. Economic theory successfully predicts the substitution of activity away from childbearing and childrearing with growing wage opportunity for women at the individual level. Yet at the country level the correlation between FLFP and TFR reversed from being negative in the 1960s to sharply positive in the 1990s (Kögel 2004; Morgan 2003). Bernhardt (1993, p. 32) has argued that "the inhibiting effect of work on fertility has been at least partially removed with the help of social and institutional arrangements," citing in particular the provision of publicly funded childcare, maternity leave, and tax benefits (Gauthier 1996). In the past several years, researchers have turned attention to various social policies and public institutions that might affect the relationship between women's work and the cost of childbearing. The reasoning suggests that the differences in both labor market participation and fertility rates in different western countries can largely be attributed to the characteristics of institutions like childcare system, parental leave arrangements, and labor market flexibility (Engelhardt and Prskawetz 2004; Rindfuss et al. 2003; Brewster and Rindfuss 2000).

In particular, it has been noted how in Scandinavian countries and France, public policies encourage both female work and childbearing by easing the childcare burden for dual earner families. This is done through public support in the form of affordable childcare services, generous maternity leaves, and protection of part-time employment. In Anglo-Saxon countries the flexible frame for part-time employment and the private childcare services offered by the market may compensate for more limited welfare provisions. By contrast, it is argued, in Southern Europe labor market rigidities and imperfections biased toward full-time or limited employment contracts, an inadequate supply of public childcare, and other institutional constraints, combine to make work and parenthood highly incompatible (Del Boca and Pasqua 2005b). It is further argued that while relaxation of these labor market rigidities (to enable more part-time employment) may increase overall female labor force participation, the shift may come with the cost of lower fertility in these settings of Southern Europe (Del Boca et al. 2005a).

The "incompatibility impasse" in Southern European countries seems to explain the survival of the negative relationship between FLFP and fertility in these settings (Kögel 2004). "Trends in the variables that would be representative for the role incompatibility hypothesis and the ease in combining work and child-rearing ... cannot be related to the trends in fertility." (Engelhardt and Prskawetz 
2004, p. 55). The childcare link seems to remain problematic. There is significant European cross-national variation in the use of public and private childcare, but little evident correlation with fertility (Kiernan 1998).

Taking a different perspective, a number of scholars have argued that no adequate theory of fertility can be developed that does not incorporate an understanding of culture (Kertzer 1995, 1997). Most prominent in this regard has been Second Demographic Transition (SDT) theory (van de Kaa 1987; Lesthaeghe and Surkyn 1998, p. 8). This approach identifies a shift toward individualization and secularization and links it to the almost contemporaneous fall of fertility to below replacement. Van de Kaa and other second transition theorists attribute this transition to a basic shift toward values emphasizing "the rights and self-fulfillment of individuals" (van de Kaa 1987, p. 5) and away from traditional family-oriented values, citing the dramatic increase in late-twentieth-century Europe in divorce, cohabitation, and non-marital childbearing. Yet the countries in Europe that currently have the lowest fertility are those showing the strongest commitment to the traditional forms of family formation, with relatively low divorce, non-marital cohabitation, and illegitimacy rates, and in the propensity of adult children to remain in their parental household until marriage and to live very close to them thereafter (McDonald 2001).

To gain better insight into these different mechanisms-secular change, labor force participation, public institutions, and family culture-it is desirable to go beyond aggregate inter-country comparisons and to look more carefully at changing fertility behavior within a country. We do so here by examining the Italian case.

\section{Low Fertility in Italy-Stylized Facts}

Italy's well-known position in cross-national comparisons of fertility trends does not tell much about the historical variation in the path of fertility decline across its regions. While it is true that fertility declined in all regions, such decline started at very different moments and proceeded at very different speeds in the various regions. In tracing the geographical pattern of marital fertility decline across Italian provinces (a lower level of aggregation than the regions) through the 19th and the 20th centuries, Livi Bacci observes that "in the areas with an early decline in fertility [the North], neoMalthusian attitudes had spread at an uneven pace because of deep economic and social differences among the various sectors of the population. [...] On the other hand in the South, where the population is perhaps more homogeneous in its socioeconomic characteristics and certainly culturally less differentiated, acceptance of neo-Malthusian attitudes was relatively slow and late and did not generate pronounced fertility differentials" (Livi Bacci 1977, pp. 180 and 181).

Replacement levels of fertility were reached in parts of the North beginning with the 1910 birth cohort, while as late as the early 1980s the TFR in a number of southern regions still stood above replacement. ${ }^{1}$ Over the last two decades of the

\footnotetext{
1 In this discussion and below we will make use of broad regions: Northwest, Northeast, Center, and South; The Northwest and Northeast together comprise the North.
} 
20th century, fertility in northern and central Italy remained stable, while the southern regions experienced continuing sharp fertility decline. By the century's end, Campania (centered on Naples), although still having the highest fertility in the country, had a TFR of only 1.5. Remarkably, Sardinia, known for its economic underdevelopment, rugged terrain, and traditionalism, and which in 1960 had the highest TFR in Italy (3.5), as might comfortably comport with both economic and SDT theory, had Italy's lowest fertility (1.04) by the end of the century (Dalla Zuanna and Crisafulli 2002, Table 2). Despite the current observed convergence of regional fertility rates, Italian regions are still marked by important variations in demographic, economic, and social patterns. This regional and temporal variation makes the Italian case an especially fruitful one for theoretical exploration of the impact of economic factors and cultural values on fertility.

Substantial variation also characterizes the levels of female labor force participation (FLFP) in the different regions, yet the correlation between regional 2003 TFR and regional FLFP (of women 25-34) is a modest -0.24 . Women in the North of Italy are much more likely to have paid employment. In the mid-1990s, $64 \%$ of women aged $20-49$ in the Northwest, but only $36 \%$ in the South did paid work. Even more strikingly, $41 \%$ of the southern women had never been in the labor force, compared to only $7 \%$ of those in the Northwest (Bernardi 1999, p. 753). Indeed, the increase in FLFP has been quite modest in the South, with the proportion of women who had ever entered the labor force rising only from $41 \%$ among those born before 1929 to $51 \%$ in the 1944-58 birth cohort (compared to $84 \%$ in the North) and little sign of any increase since then (Barbagli et al. 2003, Table 1.8). Among women with children under age six in the mid-1990s, 62\% of the Northerners and only 31\% of the Southerners were employed (Sabbadini 1999, Table 3.5). A 1998 national sample survey (Famiglia e Soggetti Sociali, FSS) asked all individuals if they had ever been in the paid labor force. The persistence of strong regional differences, particularly a North-South contrast, is clear. In the South, 50\% of the 1941-50 birth cohorts had never entered the labor force, while in the North only $20 \%$ had refrained from participation. By the 1961-70 cohorts the figure had increased to $54 \%$ in the South, while it had decreased to around $10 \%$ in the northern regions. The center of the country remained intermediate.

A third element of regional variation is represented by the ideational dimension related to gender norms and union formation. There is consistent empirical evidence that egalitarian gender norms and spousal (female) autonomy are stronger in the North (Sabbadini 1999, Table 6.3), where premarital cohabitation rates and divorce rates are also notably higher (1999: Table 4.7; Barbagli 1990). Behavioral and attitudinal indicators that tap individualization vary regionally, declining as one moves from the most secularized Northwest to the traditional South (Table 1). By contrast, there is one cultural feature that shows relatively limited regional difference and that is the propensity of young adults to live with their parents before marriage (Sabbadini 1999, Table 5.3) and to choose residential arrangements very close to their parents thereafter (Cioni 1997; Bordignon et al. 2006).

While a regional comparison leads to doubts about the adequacy of an explanation focusing on women's work, attempts to link regional level cultural differences of the sort theorized by SDT theorists to fertility levels lend little 
Table 1 Descriptive statistics for ILFI sample

\begin{tabular}{|c|c|c|c|}
\hline \multirow[t]{2}{*}{ Variables } & \multicolumn{3}{|c|}{ Mean values } \\
\hline & 1st union & 1st birth & 2nd birth \\
\hline \multicolumn{4}{|l|}{ Individual traits $(T V=$ time-varying $)$} \\
\hline Northwest (TV) [Ref] & 0.12 & 0.15 & 0.14 \\
\hline Northeast (TV) & 0.25 & 0.30 & 0.26 \\
\hline Center (TV) & 0.27 & 0.28 & 0.28 \\
\hline South (TV) & 0.36 & 0.27 & 0.32 \\
\hline Cohort 1941-50 [Ref] & 0.31 & 0.34 & 0.37 \\
\hline Cohort 1951-60 & 0.33 & 0.36 & 0.36 \\
\hline Cohort 1961-70 & 0.36 & 0.30 & 0.27 \\
\hline Mother worked & 0.36 & 0.34 & 0.34 \\
\hline Father's education elementary & 0.66 & 0.70 & 0.72 \\
\hline Father's education middle & 0.13 & 0.13 & 0.12 \\
\hline Father's education high school [Ref] & 0.10 & 0.09 & 0.08 \\
\hline Father's education post-secondary & 0.11 & 0.08 & 0.08 \\
\hline Father died (TV) & 0.05 & 0.17 & 0.16 \\
\hline Mother died (TV) & 0.02 & 0.08 & 0.06 \\
\hline Education of respondent secondary or less & NA & 0.56 & 0.59 \\
\hline Education of respondent high school [Ref] & & 0.34 & 0.33 \\
\hline Education of respondent post-secondary & NA & 0.10 & 0.08 \\
\hline Employed (TV) & NA & 0.56 & 0.52 \\
\hline In a civil union (Religious ref) & & 0.07 & 0.05 \\
\hline Entered union, Age 15-19 & & 0.16 & \\
\hline Entered union, Age 20-24 & & 0.51 & \\
\hline Entered union, Age 25-29 [Ref] & & 0.27 & \\
\hline Entered union, Age 30-34 & & 0.05 & \\
\hline Entered union, Age 35-39 & & 0.01 & \\
\hline Entered union, Age 40+ & & 0.00 & \\
\hline Age at first birth, 15-19 & & & 0.09 \\
\hline Age at first birth, 20-24 & & & 0.42 \\
\hline Age at first birth, 25-29 & & & 0.34 \\
\hline Age at first birth, 30-34 [Ref] & & & 0.12 \\
\hline Age at first birth, 35-49 & & & 0.04 \\
\hline$N$ Women (at spell onset) & 3,400 & 2,916 & 1,914 \\
\hline$N$ Women (at spell onset) & 3,400 & 2,916 & 1,914 \\
\hline
\end{tabular}

$\mathrm{NA}=$ Few women have completed education or been employed at the onset of risk (age 15) for union; subspells incorporate changes to these variables. Time varying covariates are lagged 12 months

support to this alternative. Of all marriages in Italy in 2001, over a quarter were conducted civilly, generally in the local town hall. In Italy's largest northern regions-Piedmont, Lombardy, Veneto, Liguria-the proportion of religious marriages ranged from 60 to $69 \%$. In Emilia-Romagna and Tuscany, in the heart 
of Italy's red belt, with its anticlerical and left-wing tradition, only $63 \%$ of weddings were celebrated in Church. By contrast, in no part of the mainland South was the percentage of religious marriages under 80\%, and in the deep South (Puglia, Basilicata, Calabria) it was near $90 \%$. Yet plotting regional TFR against regional percentage of religious marriages in 2003 offers little evidence of any link between secularization and low fertility (figure not shown). Italy's least secularized region using this measure was the deep southern region of Basilicata, where only $9 \%$ of marriages were celebrated outside a church, yet in 2003 Basilicata's TFR was $1.20{ }^{2}$ actually below the national average.

\section{Testing Economic and Cultural Theory at the Individual Level}

Regional-level analysis of the Italian case fails to find much support for either FLFP or SDT theories of very low fertility. We now turn to micro-level data to see whether the predicted relationships may, while obscured in regional level comparisons, be evident in individual behavior. We analyze data from the Italian Longitudinal Family Study (ILFI), the only ongoing prospective social survey in Italy. Based on an original sample of 4,404 households within which all members are interviewed (9,770 individuals $>18$ years old), ILFI includes detailed fertility histories that make it especially valuable for our analysis. The first wave of the panel took place in 1997 and we here analyze data through the first three waves (1997, 1999, 2001). Men and women aged 18-49 constitute about $60 \%$ of the initial sample. The dynamic nature of the sample means that at every wave it loses all individuals who (a) died, (b) migrated abroad, or (c) became severely impaired; and it gains individuals who (a) reach age 18 and belong to the originally sampled households, and (b) enter via union or cohabitation. ILFI is representative of the Italian population nationally. ${ }^{3}$

Looking at Italian women born in 1941-1970 we examine three crucial life course transitions: marriage, the transition from marriage to first birth, and the transition from first to second birth. It is in these cohorts-who began entering their reproductive years in 1955 and whose fertility primarily occurred between 1960 and 2001 - that the dramatic and puzzling fall of Italian childbearing is most clearly manifest.

Women in birth cohorts 1941-1970 were approximately 30-60 years old at the time of the ILFI survey. For the youngest cohorts, we cannot observe all their childbearing exposure, although our models adjust for censoring. Premature mortality of selectively differential women could affect our results, although given limited female mortality at these ages it is likely that any such effect is slight.

\footnotetext{
2 These values come from our analysis of ISTAT data.

3 ILFI, under the direction of Antonio Schizzerotto, samples a nationally representative fraction of households with a multi-stage design. Sampling fractions are identical across regions, except that Trentino is oversampled. This adds approximately 319 households from this region. We use the data with the filter that includes only the nationally representative portion. Results with the augmented sample show little difference. This also makes it unnecessary to weight descriptive statistics.
} 
We analyze each of these three transitions with Cox regression models and introduce a set of covariates designed to capture both fixed and time-varying traits of the women. Of course, it is only women who experience one of these cumulative life transitions who join the population of women at risk of experiencing the next transition. Thus, we can expect that successive transitions tap a pool of women who are increasingly selective. We present pooled and cohort-specific models, after having explored a large number of alternative specifications.

Following our interest in weighing the potential value of theories that focus on women's work on the one hand, and secularization (SDT theory) on the other, we pay particular attention to two variables: (1) whether the woman is in the work force, which is lagged by one year so as to capture a possible causal effect; and (2) whether the woman was married in church or in a civil marriage. The number of cohabiting couples in the sample is too small to incorporate a separate measure of this form of union. We regard civil marriage as a compelling indicator of the secularization of Italian society, consistent with the concept of the Second Demographic Transition. Just because civil marriage is a strong measure of secularization, it has the limitation for our purposes of being relatively uncommon among the oldest cohorts.

In the analysis to follow, we organize our presentation by event: first union, first birth, second birth. In each case we introduce overall descriptive differentials for the outcome by region and cohort. Then we move to multivariate Cox regressions. Table 1 presents descriptive statistics for all covariates in the ILFI analysis.

\section{First Union}

Among the factors often cited as contributing to very low fertility is a postponement of marriage to ever-later ages. Such a factor might be thought to be especially influential in Italy, where childbearing remains closely tied to marriage. Italy has, in fact, been among the countries that have recently experienced a sharp rise in the age at first marriage. From 1985 to 2001 women's mean age at first marriage rose dramatically, from 23.8 to 28.5 . $^{4}$

In analyzing the transition to marriage we follow convention in taking age 15 to indicate the onset of risk and so model the duration from age 15 to (age at) first union. Women are censored at the time of the survey if they have not yet entered a union. In this analysis we take only formal unions (civil and religious marriages) to constitute an event ending the spell. Cohabitation is relatively rare in Italy; thus, the sparseness of the events made cohabitation difficult to analyze separately. Furthermore our preliminary analysis suggested that cohabiters may be qualitatively different from those entering formal unions.

In descriptive data via Kaplan Meier survival analysis, we observe dramatic differences by cohort, with the youngest cohort, born in 1961-70, showing a marked slowdown in marital timing while in both the 1941-50 and the 1961-70 cohorts

\footnotetext{
4 The 1980 figure is from Council of Europe, Recent demographic developments in Europe, 2004, Table 2.3. The 2001 figure is from ISTAT, Matrimoni, separazioni e divorzi, anno 2001, Table 1.4.
} 


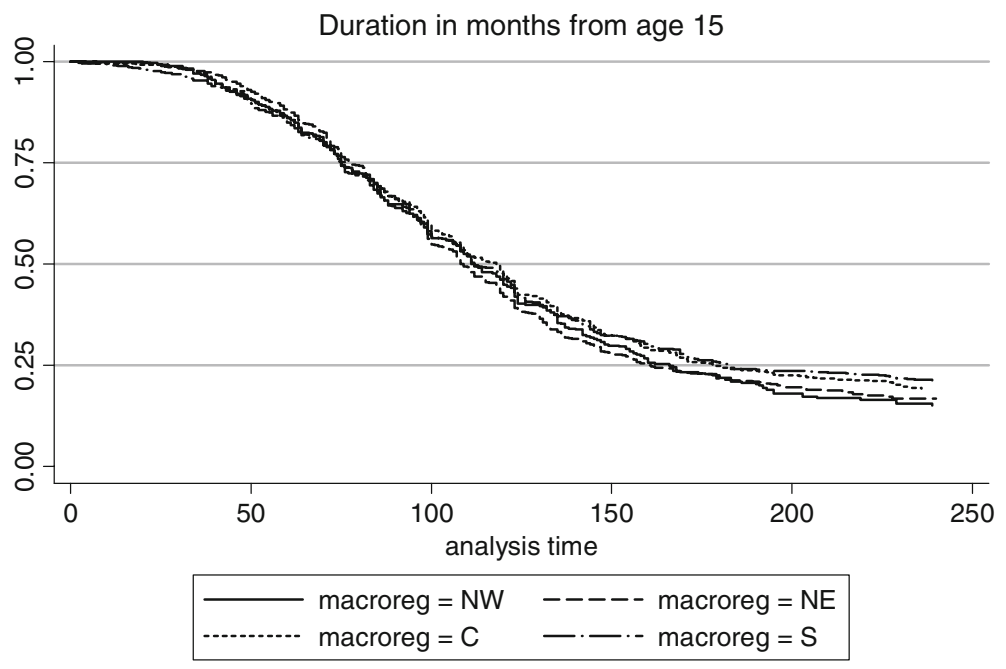

Fig. 1 Duration to union by macroregion

about two-thirds of women had married by age 25 , only $39 \%$ of women in the youngest cohort had done so by that age. In fact, our Kaplan Meier data indicate that after 20 years of exposure (accounting for censoring) - that is at age 35-about onethird of the youngest cohort had yet to enter a formal union. ${ }^{5}$

Figure 1 presents the survival curves for the duration to first union, drawn separately by region. We define "macroregion" to be an aggregation from 20 administrative regions into 4 larger regions, as used in our introduction and by other analysts. Our entire ILFI sample born since 1940 (age 30-60 at time of survey) is represented in these graphs. Here we observe only modest differences for the rate of entry into first union. This lack of regional difference in marriage rates is itself noteworthy, in that, as we shall show below, our geographic depictions of fertility rates point to significant differences across the four macro regions of Italy.

We extend these descriptive portraits with regression models, in which we test for the relative influence of cohort, region, and a number of potentially influential traits of each woman. These include family background factors-mother's work experience, father's education, death of mother and father-as well as the woman's own education and employment status. Our model specifications are successively more inclusive, although we only present selected specifications here. ${ }^{6}$

\footnotetext{
5 To the extent that the very youngest members of the youngest cohort have not had this full exposure, their differential behavior (such as more rapid entry into marriage after prolonged delay) will not be represented in these graphs.

6 In most cases individual covariates are fairly robust to alternative specification, particularly the addition of other traits presumed to be exogenous. We have estimated alternative models (not shown) that include covariates whose causal priority is more questionable. Even when we can establish temporal priority, one can ask whether these characteristics_living with parents, self-classification as a "student" —are not in fact jointly determined with the marriage and family building choices we model. After estimating pooled models, we split the sample by birth cohort and repeat the estimation of the preferred model.
} 
Table 2 presents Cox regression models for the prediction of duration from age 15 to first union. Coefficients are presented in relative risk format, and hence indicate the proportional shift in the baseline hazard due to a unit change in that variable, i.e. membership in that category.

Model 1 includes only cohort and region. Unsurprisingly, given the known secular trend, we observe appreciable cohort differences. Women in the youngest birth cohort (1961-70) marry at about 52\% of the rate of women in the reference (1941-50) cohort. There are essentially no differences between the two oldest cohorts. Regional differences are very modest and are not significant at conventional levels. Again there is no appreciable difference between the Northwest macro region (reference) - the area identified with the earliest attainment of very low fertility - and the Northeast and the Center. Women in the South exhibit a relative risk of $90 \%$, but this difference is not statistically significant. ${ }^{7}$

Our next model introduces the standard set of covariates suitable for the prediction of first union. As mentioned above, these include measures of economic background, parental mortality, woman's own education, and, especially, employment. (Death of mother, death of father, and woman's employment are all timevarying covariates.) In the presence of these additional personal traits the effects of region and cohort shift modestly. Regional effects become more pronounced (with all regions exhibiting lower relative risks compared to the Northwest once controls are introduced). Women in the South are now shown to have about $20 \%$ lower marriage hazard rates $(\mathrm{RRR}=0.818)$, and this is highly significant. The secular decline in propensity to marry remains, indicated by the significance of the dummy variable for the 1961-70 birth cohort. Its magnitude is reduced, however. The increase in the magnitude of the effect of regional dummy variable for the South upon the inclusion of the employment measure is suggestive of a slightly different employment-marital regime in that region. Once we control for employment, women born in the South are actually even less likely to marry than women in other regions; their lower rate of employment partly masks this.

Several other family background factors are strongly predictive of this first step in family formation. Women whose mothers worked when the women were aged 15 exhibit a marital hazard rate about $12 \%$ below those of other equivalent women. Women whose fathers had low or no education marry at significantly higher rates. We find no effect of parental mortality on union formation. ${ }^{8}$ The education of the women is quite strongly predictive of the rate of entry into marriage, showing a Ushaped relationship. Women with low levels of education have a marriage rate $64 \%$ above women with moderate levels of education. On the other hand, women with high levels of education exhibit a hazard rate for duration to marriage $37 \%$ above the middle group. ${ }^{9}$

\footnotetext{
7 Women in the South macro region constitute a fairly large portion of our ILFI sample. Of the 7,250 women who initiate spells in our data file, $35.0 \%$ are living in the South at age 15 .

${ }^{8}$ By the time of the survey, $17.5 \%$ of the women had experienced the death of their father and $7.1 \%$ the death of their mother.

9 Secular changes in educational attainment across these cohorts may confound these results, esp. if relative education rather than absolute year of attainment points to the mechanism of interest.
} 


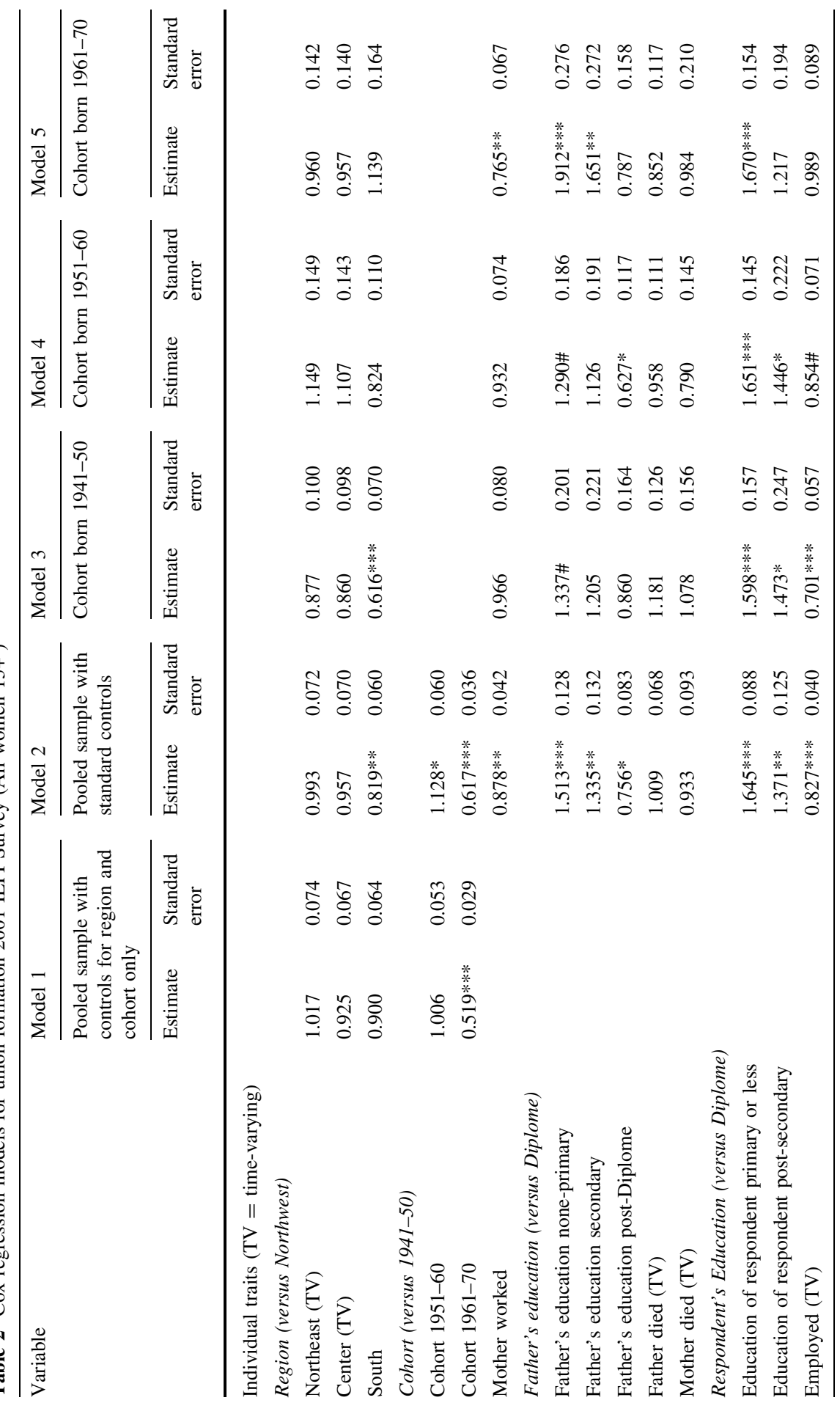




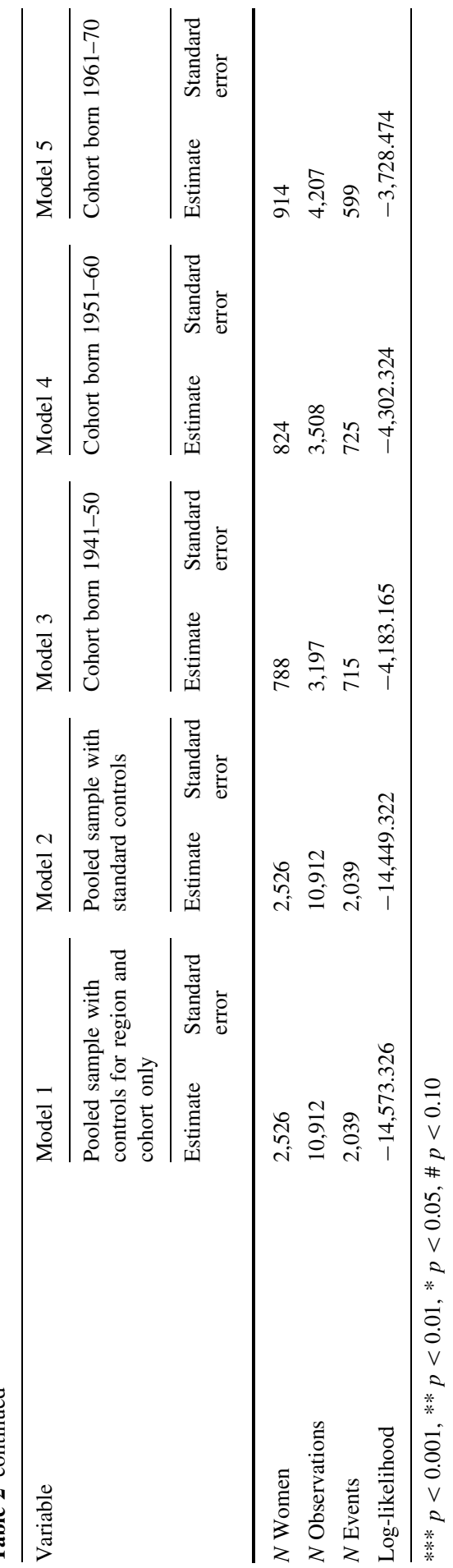


Employment of the woman herself is of particular interest. Much contemporary theory about very low fertility, as discussed above, would suggest that employment would depress the family building activity of contemporary women. We ask not only whether this is true, but also the magnitude of the effect and the extent of its effect across time (birth cohorts) and across the successive family-building events we examine with ILFI.

Model 2 of Table 2 indicates that on balance women's employment operates to significantly and appreciably reduce the rate of entry into marriage to about $83 \%$ of otherwise equivalent women. Clearly, net of these other traits, employment lengthens the duration to marriage. This aggregate result (cohorts pooled) offers support for the view that the decline in fertility commences with lower rates of entry into marriage, in turn, partly driven by women's employment. ${ }^{10}$

Models 3-5 split the cohorts and repeat the analysis; thus, these models allow the effects of traits to differ across the three cohorts of women. Women in the 1941-50 cohort have passed beyond the standard reproductive span by the time of the ILFI 2001 survey wave. Thus information for their union formation (as linked to fertility) and childbearing should be complete. Some $88 \%$ of this cohort is observed to marry. For these women we find clearly visible effects of region, woman's own education, and employment. Parental background traits do not show through here. Women in the South make the transition to first marriage more slowly than women from other regions of Italy. (Women in the Northeast and Center show relative risk rates below unity, but these are not statistically significant.) At the same time we find that women whose education is low or high experience more rapid marriage - the Ushaped effect. This statistical result may be worth particular consideration in this cohort, as the apparent inconsistency may point to competing mechanisms linked to some of the overarching processes we identified at the outset. Certainly aspiration for education and labor market participation are intertwined. As in the pooled results working women make the transition to marriage less quickly, about $30 \%$ below the transition rate of otherwise equivalent women.

Some elements of this nuptiality process change by the time the next cohort, born 1951-60, is observed. In this case, regional differences are muted further, with almost no differential at all among Northeast, Northwest, and Center. The point estimate for women from the South indicates a lower rate of transition into marriage, but this difference is not statistically significant. Personal and parental traits have some predictive value, in a direction mostly consistent with an effect in which higher socioeconomic status retards marriage. Women whose fathers had little education experienced more rapid rates of marriage, while children of highly educated fathers experience slower marriage. The woman's own education matters a good deal, and again, a U-shaped pattern is observed: poorly and highly educated women are quicker to marry.

\footnotetext{
${ }^{10}$ We also estimated a model that split the employment effect into (separate dummy variables for) fulltime and part-time work. In the pooled model and some cohort-specific models, the individual dummy variables were statistically significant; however, we always failed to reject the hypothesis of the constraint that the two coefficients are equal. Thus, we accept the hypothesis of equivalence and model the employment effect overall.
} 
The employment effect is statistically significant, although its strength does not match that found in other cohorts. In this middle birth cohort, we observe that employed women enter unions at about $15 \%$ lower rates $(R R R=0.856)$ than other equivalent women.

Our final cohort comparison turns to women born in 1961-70, who are aged 3141 at the time of the survey. We observe 914 such women and nearly two-thirds of them have married as of the survey date. This youngest cohort differs yet again from the older two. Regional differences in rates of marriage transition have moderated considerably. (No coefficients are even marginally significant.) Yet personal background traits are predictive. Women whose fathers had little or no education (a decreasing fraction of the population of women over time) entered into marriage more quickly, while those whose mothers worked made this transition more slowly. ${ }^{11}$ The U-shaped effect of woman's own education is visible once again, although the only significant effect indicates that poorly educated women are quicker to marry.

Perhaps most notable in the Cox regression of this youngest cohort is the lack of any effect of the woman's own employment. It appears that with women's work becoming more common and, perhaps, normatively more accepted, it no longer has the effect on discouraging marriage that it formerly did.

\section{First Birth}

We turn now more directly to our individual-level fertility analysis with a look at the transition from marriage to first birth. Since cohabitation is relatively uncommon in Italy, and since childbearing outside of a formal union is relatively rare (although increasing), we exclude cohabiting individuals from the risk set. ${ }^{12}$

In our sample, some $92 \%$ of all women who had entered a formal union experienced a birth by the 2001 wave of the ILFI survey. As was to be expected, successive cohorts show a slowing down of transition to first birth. While nearly $90 \%$ of the 1941-50 cohort experienced a birth within 5 years of marriage, only about $80 \%$ of the 1961-70 cohort did so. But unlike the pattern we found in transition to first marriage, the transition from marriage to first birth showed clear regional differences across all cohorts (Fig. 2). Women in the South proceeded more quickly to a first birth after marriage than did women elsewhere; $92 \%$ of women in the South had a child within five years of marriage compared to $83 \%$ of women in the Northwest.

A simple Cox regression model with regional and cohort covariates alone confirms these graphical differences. Table 3 Model 1 points to statistically

\footnotetext{
${ }^{11}$ In these two youngest cohorts (but not in the 1941-50) cohort an alternative model that included the woman's number of siblings indicating that woman who came from larger families of origin married sooner. Since this covariate did not influence other covariates and was always non-significant in the first and second birth models, we have not included in the basic models we present.

12 Alternative analyses, including a dummy covariate for "cohabitation," showed lower fertility (lower than civil union) for this group, but included relatively large standard errors (small N). At the same time, qualitative inference for other covariates is not altered by excluding cohabiting women from the model.
} 


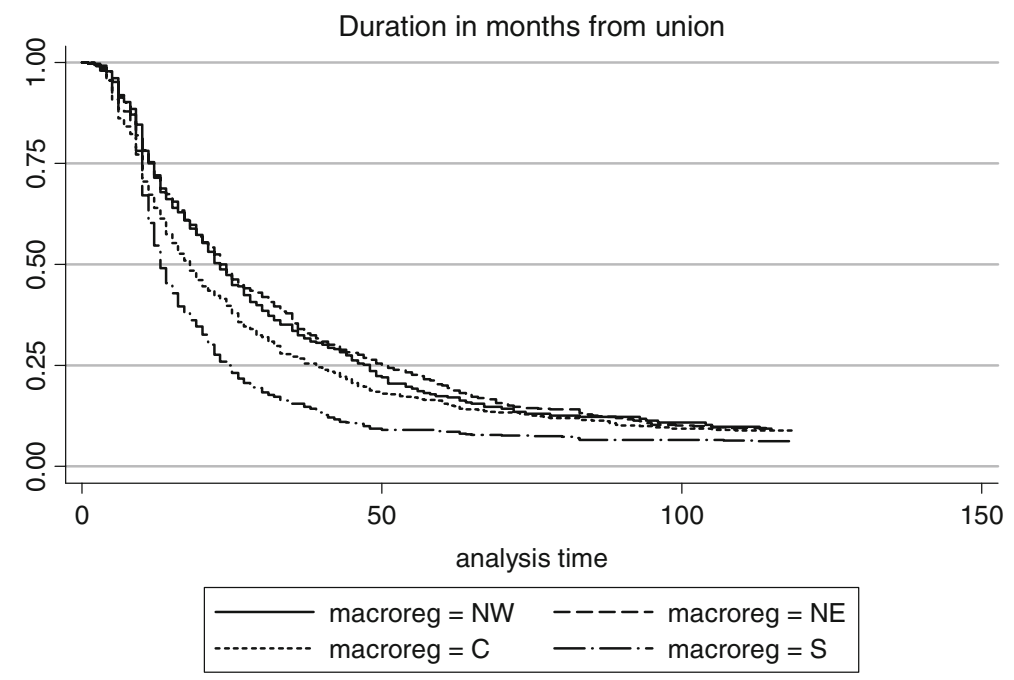

Fig. 2 Duration to first birth by macroregion

significant and high rates of childbearing in the Center and South, with progressively slower rates of the transition to parenthood across cohorts. Model 2 introduces the standard set of personal covariates into the model. This model includes covariates used above for union formation, but, to provide a test of SDT, adds a dummy variable for type of union: civil marriage (versus religious). Economic theory argues that woman's employment (a time-varying covariate) should serve to decrease the rate of transition to first birth. Education and socioeconomic background should work in corresponding ways, with higher status women slower to make the transition. A strict interpretation would suggest that regional (and cohort) differences should be reduced or even eliminated on the basis of these additional controls. Persistent effects not consistent with the standard explanation would suggest that regional differences and marital union type differences would remain, even in this more comprehensive model.

In Table 3, Model 2 we find only modest effects of some of the socioeconomic background factors; mother's work, father's education, and parental mortality are all non-significant in this model. Even the woman's own education offers little additional power to predict first birth transition. In this model regional and cohort effects are reduced only slightly in magnitude from Model 1 . Thus women in the Center and South make the transition from marriage to first birth at higher rates, while women in recent cohorts make the transition more slowly, even after adjusting for other characteristics.

We also include in this model covariates for woman's age at marriage. Collectively these five dummy variables (with marriage at age 25-29 as the reference) are highly significant. We observe that women who marry at the youngest ages make the transition to first child more rapidly, all else equal. Women who marry at ages 35-39 make this transition much more slowly than the women in the 


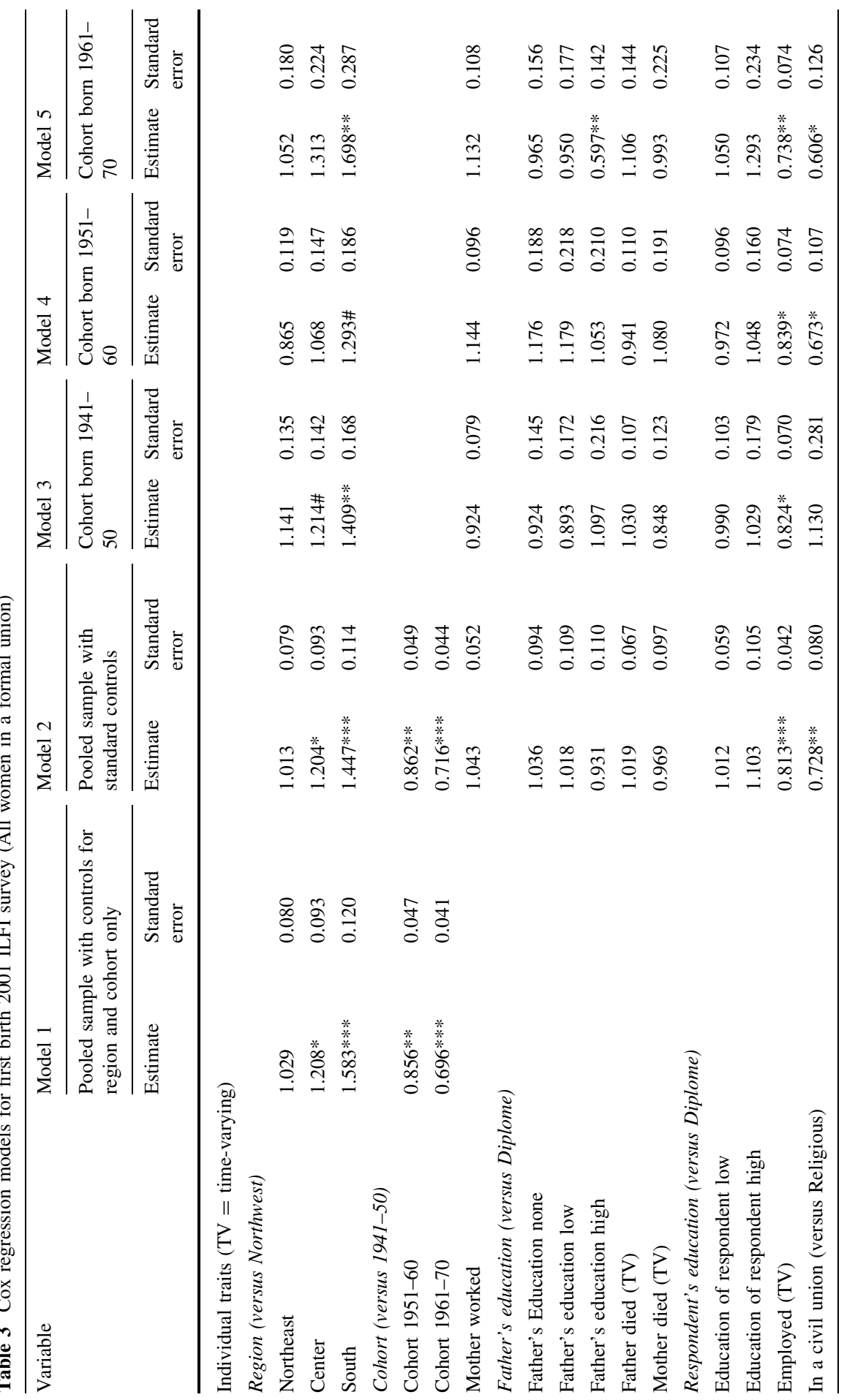

\section{글 Springer}




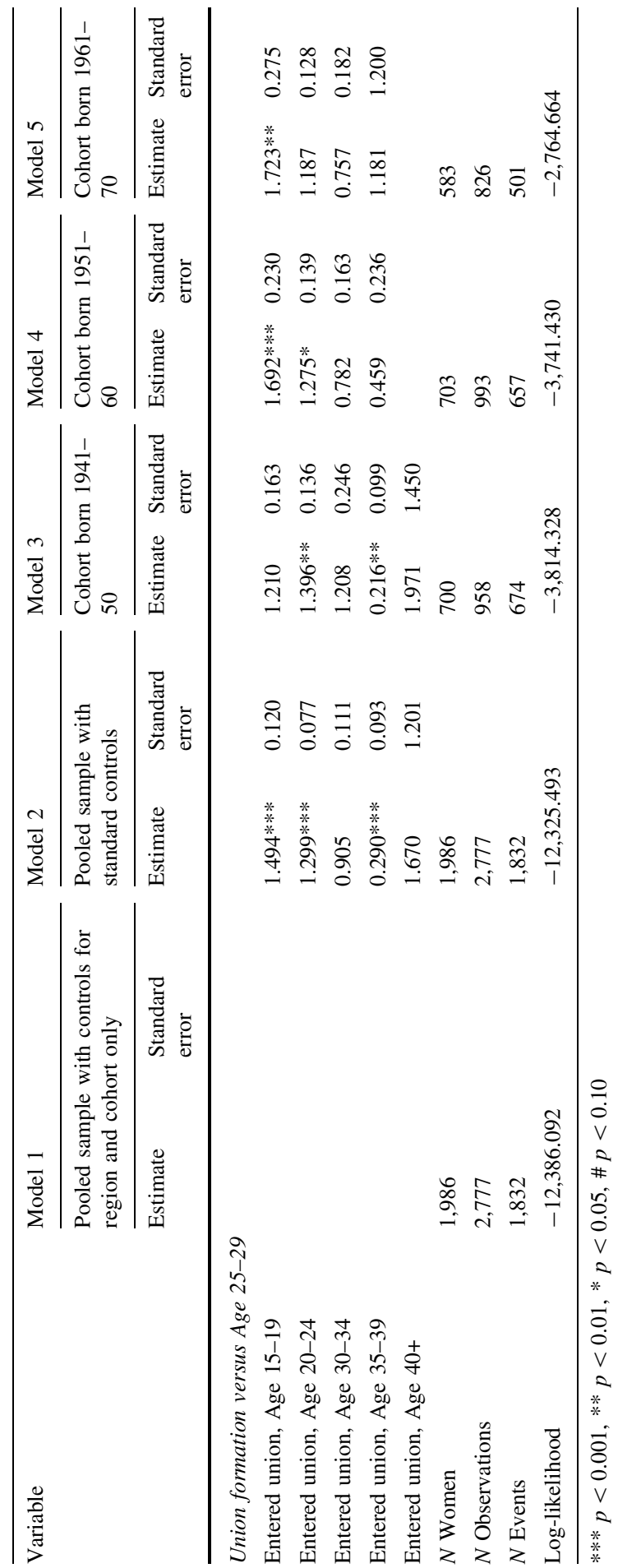


25-34 cohorts. ${ }^{13}$ There is no evidence of hastening the childbearing transition for women who enter (first) marriage at a later age.

Importantly, our primary measures of both FLFP theories and SDT theory regarding very low fertility-woman's employment and marital union type-are strong predictors of the progression from union to first birth. The relative risk of first birth transition for employed women is 0.81 and is one of the most powerful predictors in the model. A similar effect (0.73) is indicated for women in a civil union compared to a religious union. Again this effect is highly significant. For a woman who is both employed and in a civil union-together indicators of departure from a more traditional family building style-the relative risk ratio is 0.59 $(\mathrm{RRR}=0.813 * 0.728)$. In other words, for such women their rate of transition from marriage to first birth is $59 \%$ that of otherwise equivalent women.

We extend the analysis to look at this transition separately by cohort, and estimated coefficients appear in Models 3-5 of Table 3. In the 1941-50 cohort we find that women in the Center and South experienced higher rates of first birth transition. In the complete model, almost no covariates for background socioeconomic traits are statistically significant. This older cohort had few cases of civil marriage and so it may not be surprising that no significant differences between women married civilly and religiously can be found here. We still find a strong effect of employment $(\mathrm{RRR}=0.824)$, not much different from the model which pools across all three birth cohorts. It is quite clear that employment, even in these relatively early cohorts, is strongly and negatively associated with the transition to first birth. ${ }^{14}$ Coefficients for age at union are not particularly consistent or stable. Still there is evidence that women who marry at younger ages (15-24) make the first birth transition more rapidly.

The story for the 1951-60 cohort differs only moderately. Again the background traits of parental characteristics and woman's own education do little to improve prediction in the model. Notably, regional effects are not visible. While women in the South and Central macro regions exhibit somewhat higher rates of transition, the associated coefficients do not achieve statistical significance. (There are 703 women at risk in this cohort.) By contrast, effects for employment and for union status are strong and highly significant. Employed women have a relative risk of first birth about $16 \%$ below other equivalent women in their cohort. Women in a civil union have a 33\% lower relative risk. As for the pooled sample these two traits in combination (employed women in a civil union) predict a much lower rate of entry into childbearing. Here again, women who marry at an early age (15-24) display a more rapid rate of making the transition to first birth.

The story for the 1961-70 cohort differs in several important respects from the older two cohorts. These women are about age 31-41 in 2001 at the time of the last IFLI wave we use here. They thus have not completed their reproductive span, so that any additional timing shifts anticipated after 2001 cannot be captured by our

\footnotetext{
13 Further work will investigate what role premarital pregnancy may play in explaining the higher rates of first birth among the youngest age groups.

14 Coefficients for parental traits do not achieve statistical significance at conventional levels when employment and woman's own education are excluded from the model.
} 
data. Regional differences re-emerge in this cohort. Notably women in the South $(\mathrm{RRR}=1.70 ; p<0.001)$ proceed much more rapidly to their first birth. Women in the Center also progress more rapidly, although this difference is only significant at the $10 \%$ level. Parental background traits are again of modest predictive value, although we observe that women with fathers of the highest level of education have lower childbearing rates $(\mathrm{RRR}=0.597 ; p=0.03)$. In this youngest cohort of 583 women, we observe less of an effect of age at first union. What does show through is that women who marry as teens have much higher transition rates than those who marry in their twenties and early thirties. Here, though, the impact of bridal pregnancy undoubtedly weighs heavily.

Being employed and in a civil (versus religious) union once again exert strong downward effects on predicted fertility. Employed women exhibit hazard rates some $30 \%$ below non-working women. As was the case with previous cohorts, the combination of working and being in a civil union serves to lower the predicted rate of transition from union to first birth appreciably, here by over one-half.

We also investigated alternative models for the transition to first birth. In parallel to our examination in the case of union formation, we tested for the effect of parttime versus full-time employment. In a test of constraints across coefficients, we accept the null hypothesis of no difference in the effect of full- and part-time employment. Also, we tested for the influence of the number of siblings of the woman. A greater number of siblings might be expected to proxy a family background in which traditional roles and/or larger family sizes are valued. (In turn, this expectation would lead to a prediction of first birth occurring more rapidly.) We find no evidence of this, as the covariate for number of siblings provided no additional predictive power beyond the characteristics already in the model.

We also examined an alternative model that included interaction terms between woman's own education and age at union. These are added to both the pooled and cohort-specific models, in which the first-order covariates for education and age at union appear as in Table 3. The joint test of the group of covariates indicates that they are not collectively significant. This indicates that there is no identifiable further alteration of the effect of education across women who enter unions at differing ages.

\section{Second Birth}

The third and final element of our event history analysis focuses on second birth. In our ILFI sample of women in the cohorts born between 1941 and 1970, some 1,914 have a first birth, and of this group, $72 \%$ go on to bear a second child within the observation period. Not only is this a (necessarily) smaller sample than the number of women at risk of first union and first birth, it is more selective as well.

There are no pronounced cohort differences in the transition to second birth, although it is evident that the 1941-50 cohort made the transition from first to second birth more rapidly than succeeding cohorts. Tabulations of the survivor function point to 5-year transition fractions of 59\%, 51\% and 53\% for the cohorts successively. The youngest cohort is slow to make the transition for about 4 years 


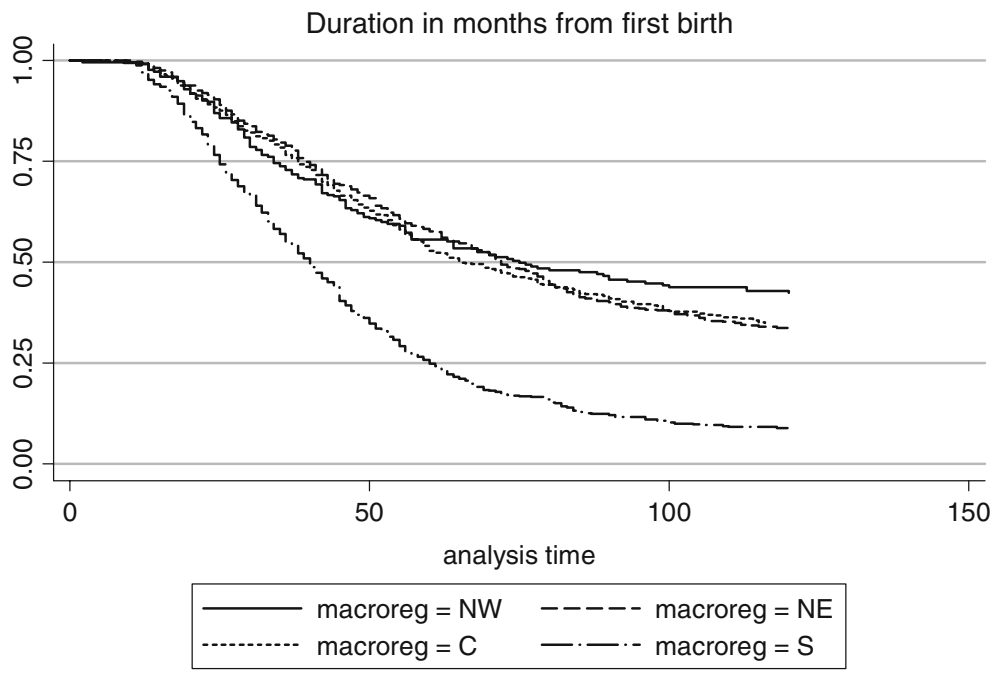

Fig. 3 Duration to second birth by macroregion

following first birth, but after that point makes the transition more rapidly so that it reaches a crossover with the other two cohorts within a decade of exposure. It is worth recalling that the underlying sample contains more women in each of the older two cohorts than in the youngest, since the youngest cohort is least likely to marry and have a first birth, requisites for being in the risk set for second birth. Regional differences are noteworthy. While Fig. 3 shows no discernible differences across Northeast, Northwest, and Central for the five years following first birth, women in the South make this transition much more rapidly.

Table 4, Model 1 points to statistically significant and somewhat higher rates of childbearing in the Northeast and the Center, compared to the Northwest. But strikingly, the relative risk for the South is nearly double that for these other two regions and close to three times the rate found in the Northwest. Cohort effects are present, with both the 1951-60 and 1961-70 cohorts displaying a hazard rate about $15 \%$ below that of the reference group of women in the 1941-50 cohort. The fact that the 1951-60 cohort differs little from the 1961-70 cohort in second-birth transition while it does differ in first birth transition (see above) suggests that restriction of fertility at higher parities (even 2 nd) had begun to make its way into family building practice in this middle cohort, who were themselves passing through key years of the reproductive span in the 1970s and 1980s.

Model 2 includes the standard set of covariates as in the models above. Addition of these individual-level traits does virtually nothing to attenuate either the regional or the cohort effects. Women from the Northeast and the Center display hazard rates that are $21 \%$ and $23 \%$ higher than women in the Northwest, while again, strikingly, women from the South experience the second-child transition at 2.6 times the rate of women in the Northwest, even controlling for all of these individual-level traits. Women whose mothers worked when the women were aged 15 show higher rates of second birth transition. While this might be seen as contrary to expectation it may 


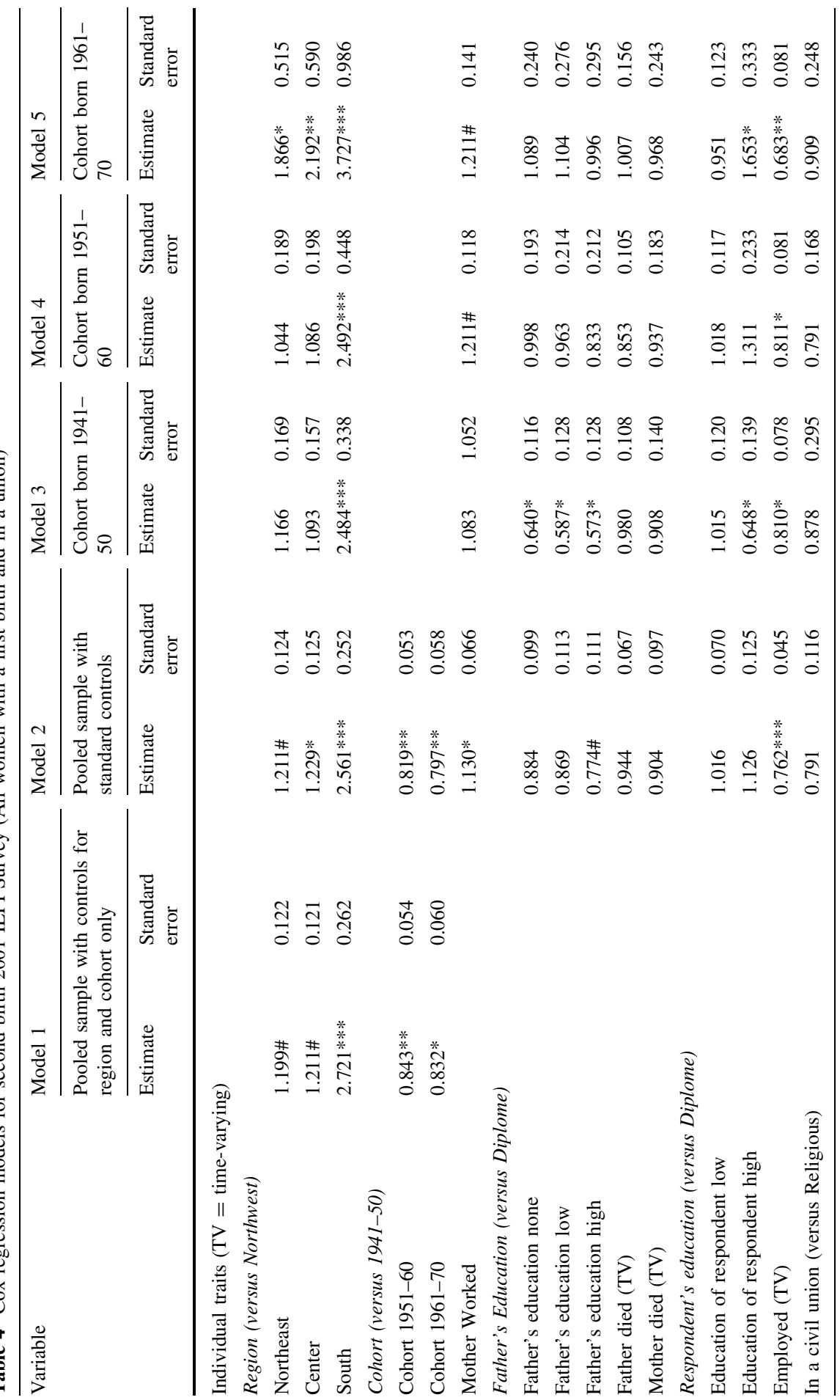




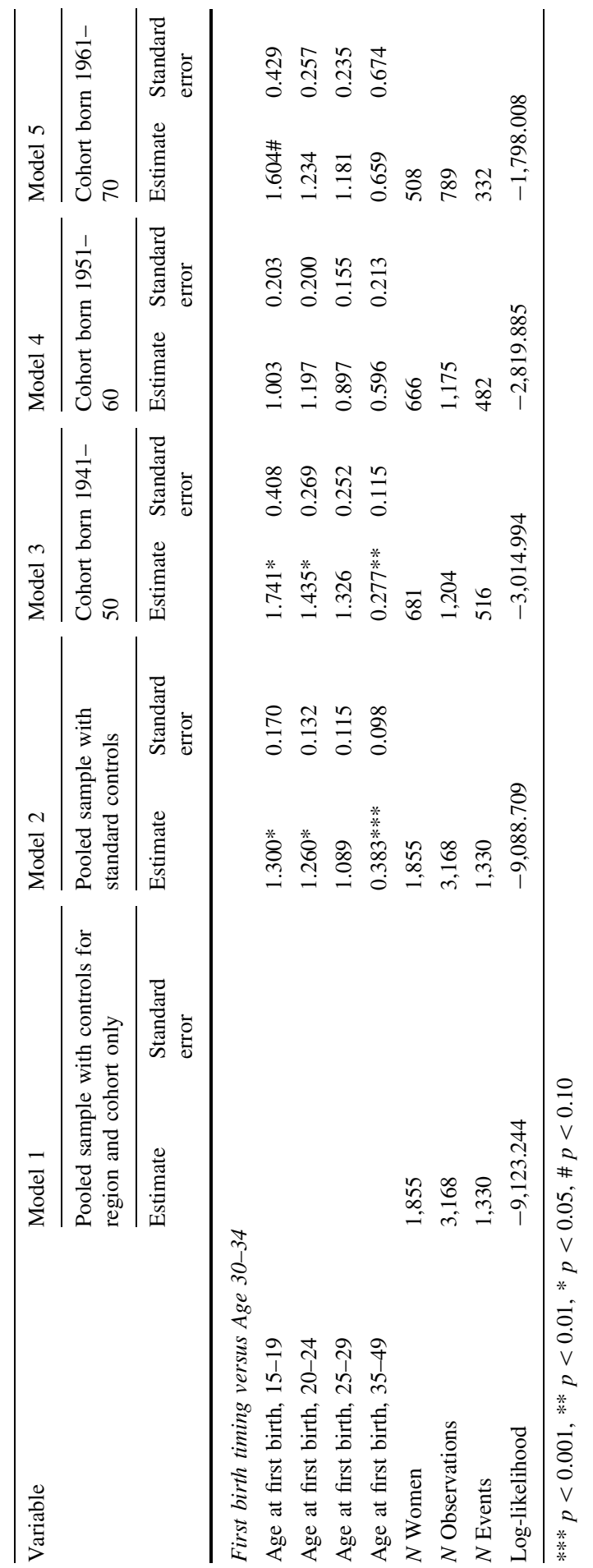


reflect an intergenerational pattern of scheduling work and reproductive careers in which the second birth is hastened by the existence of a maternal role model balancing work and reproduction. Father's education and that of the woman herself carry little predictive value in this model. Those who have their first child at an earlier age also made the transition from first to second child more quickly. Broadly speaking, women who bore their first child before age 25 moved on to the second child at about $25 \%$ higher rate than women whose first birth occurred when they were aged 25-34. As in the case of both other transitions considered above, employed women and those in civil marriages exhibit dramatically lower second birth transition rates, with the combined effect of lowering the hazard rate by about $40 \% .^{15}$

As with the models reported for the previous two transitions, Models 3-5 here repeat the analysis by cohort. In the 1941-50 cohort, regional differences are quite pronounced, with the South relative risk about 2.5 times the Northwest and the other two regions intermediate and non-significant. For this cohort of 681 women, about $75 \%$ of whom experienced a second birth, those with father's education at the low or high end of the distribution are shown to have slower rates of progression to the second child. Women with limited education show no difference from women with middle-range education, but women with high educational levels have much lower second birth rates $(\mathrm{RRR}=0.648)$. Employment continues to have much the same effect as before, lowering predicted fertility by about $20 \%$. The point estimate for civil union indicates reduced fertility, but civil marriages are rare in this cohort and the estimate does not achieve statistical significance.

In the 1951-60 cohort, regional effects are similar to those found in the older cohort. Women in the South bear their second child at rates about 2.5 times those in the Northwest; women in the other regions are intermediate and their differences are not statistically different from the reference region. No parental or personal traits for education or parental loss are statistically significant for this cohort of 666 women, some $72 \%$ of whom bear a second child. Working women exhibited rates of childbearing reduced by about one-fifth $(\mathrm{RRR}=0.811, p=0.036)$. There were no statistically significant differences by union status or by age at first birth, although the presence of this latter group of dummy variables does alter other coefficients.

In our youngest cohort, 1961-70, we have 508 women who initiated a spell with a first birth, and $65 \%$ of them are observed to go on to a second birth. Here the regional rankings are similar to earlier cohorts, but we observe particularly depressed fertility among women in the Northwest. Southern women have rates of second birth almost four times as large as those in the Northwest (RRR $=3.73$, $p<0.001)$. Rates for the Northeast and Center are about double the Northwest.

Few personal and parental background traits help predict this fertility transition, save one: women's own education. Women in the highest education category exhibit transition rates to second birth $65 \%$ above other women. This may represent

\footnotetext{
15 An alternative model tested (via dummy variable interaction) whether employed women in the South behaved differently from other women. This had no additional predictive power. Small numbers of women are in a cohabiting union or not in any union during some of the time exposed to the risk of a second birth. Models which included dummy covariates for these two traits indicated significantly lower relative risks for such women. Since other coefficients were robust to these alternatives, we have used the simpler specification for ease of exposition.
} 
a conscious fertility compression strategy for such highly educated (and professional) females. Working depresses the rate of transition to the second birth; its effect is significant and larger in magnitude than for previous cohorts.

As with the first birth transition, we investigated alternative models for the transition to second birth. Again, we find no statistically significant difference between the effect of part-time and full-time employment. As before, the sibling covariate was non-significant. And finally, we again examined a model for an ageeducation interaction. Here we include dummy variable for the interaction of covariates for woman's own education and her age at first birth across the pooled and cohort-specific estimations. ${ }^{16}$ Once again, the joint test of the group of dummy variable interaction terms was non-significant; thus, the effect of education across women who bear their first child at differing ages is not seen to differ.

\section{Conclusions}

The Italian case has undermined confidence in the two most prominent theories of very low fertility: one that focuses on increases in women's labor force participation, and the other on a shift to less familistic and more secular values. But if we move away from the country comparisons that tend to dominate this literature and instead examine fertility in Italy in the context of individual lives, it becomes clear that each of these theoretical approaches has value. At the same time, each approach has limits. It is particularly interesting to discover that even regionallevel comparisons within Italy provided little support for either of these two influential theoretical perspectives. It required individual-level life course data and longitudinal analysis to demonstrate that both hypothesized sets of relationships actually do play a role.

Indeed, our micro-level analyses showed that women's employment has a strong impact on Italians' marriage and fertility behavior. Until the most recent cohort, working women married more slowly. And throughout all cohorts, women's participation in the labor force had a consistently negative and powerful impact on their childbearing. Women who were working were $20 \%-30 \%$ less likely (using odds ratios from cohort-specific models) to make transitions to first and second birth. Similarly, although the statistical significance was marginal due to the small number of cases, there is intriguing evidence that those choosing a civil marriageand hence embracing more secular values and less subject to the church's influence-had lower birth transition rates than those who were married in church. Clearly, this relationship merits further study as new data become available.

Yet even after controlling not only for women's employment and civil marriage, but also for a host of family and individual characteristics, very pronounced regional effects were evident. This suggests that Italy's regional differences are tapping contextual effects that are not captured by existing economic or SDT theory and may be rooted in social networks, provision of local public services, availability of

\footnotetext{
16 These models strain the more modest sample size for cohort-specific analysis, and some interactions could not be estimated. Suffice to say no compelling evidence appears for age-education interactions.
} 
kin, and, especially, sociocultural norms regarding family building. The dramatic size of these regional effects offers strong evidence of the need to look beyond traditional economic and SDT theories in explaining declines in fertility.

Our work suggests several avenues for future research. First, effort should go into further substantive specifications of these persistent regional differentials. Contextual covariates, although not easy to assemble, might point to some of the regional and local features - both social and policy-based - that could help promote or retard these three transitions. Second, one might consider Livi-Bacci's contention that, contrary to SDT theory, it is the very surfeit of familism in societies such as Italy that contributes to very low fertility (Livi-Bacci and Savini 2000; Livi-Bacci 2001; Dalla Zuanna 2001). He argues that the intense interdependence between generations is leading to a prolonged period of dependency in the younger generation, and that this leads the younger generation to avoid, postpone, or in any case limit their assumption of parental responsibilities and commitments. Although this theory has proven difficult to test, the argument is provocative and, given the prominent place occupied by familistic societies among the pioneers of very low fertility, worth putting to the test. ${ }^{17}$ Third, it is important to look more closely at gender relations as a potential key to explaining very low fertility. Focusing on gender relations rather than familism, McDonald has offered an alternative explanation for the Italian paradox. Drawing on Mason's (1997) work, he (2000, pp. 427-8) hypothesizes that "very low fertility in advanced countries today is the outcome of a conflict or inconsistency between high levels of gender equity in individual-oriented social institutions and sustained gender inequity in familyoriented social institutions." From this perspective, the fact that Italy and Spain have such low fertility is explained by the preservation of a traditional gender system in the context of expanding labor force opportunities for women. All three of these lines of expansion could flow from (and be consistent with) our work, although developing well-specified empirical tests remains a challenge.

Perhaps most interesting for social science theory more generally, our work serves both to recover and to challenge economic and cultural approaches to explaining demographic behavior. While neither prevailing economic theory (FLFP) nor SDT theory aimed at explaining very low fertility should be wholly dismissed based on the Italian evidence-indeed each very likely points at forces that have had an impact on Italy's dramatic fertility decline-together they only partially explain the Italian case. The lessons that Italy has to provide for our understanding of very low fertility are still largely untapped, awaiting a fuller exploration of the social, institutional, and cultural matrices in which the decision to have children is made.

Acknowledgments Based on research supported by grants from the National Institute of Child Health and Human Development (R01 HD048715) and the National Science Foundation (BCS 0418443). An earlier version of this article was presented at the 2006 meetings of the Population Association of America in Los Angeles. Thanks to Gianpiero Dalla Zuanna and Hans-Peter Kohler and anonymous

\footnotetext{
17 A particularly intriguing aspect of this is our finding (not shown) that women with more siblings transition to marriage more quickly in the cohorts born since 1950, yet there is no discernible sibling effect on subsequent fertility of these women.
} 
referees for their comments on earlier drafts of this paper and to Kelley Alison Smith for editorial assistance.

\section{References}

Barbagli, M. (1990). Provando e riprovando: Matrimonio, famiglia e divorzio in Italia ed in altri paesi occidentali. Bologna: Il Mulino.

Barbagli, M., Castiglioni, M., \& Dalla Zuanna, G. (2003). Fare famiglia in Italia. Bologna: Il Mulino.

Becker, G. (1976). The economic approach to human behavior. Chicago: Un. Chicago Press.

Bernardi, F. (1999). Dinamiche familiari e partecipazione al mercato del lavoro delle donne sposate. In P. De Sandre, A. Pinnelli, \& A. Santini (Eds.), Nuzialità e fecondità in trasformazione: percorsi e fattori del cambiamento (pp. 745-760). Bologna: Il Mulino.

Bernhardt, E. M. (1993). Fertility and employment. European Sociological Review, 9, 25-42.

Bordignon, F., Dalla Zuanna, G., \& Michielin, F. (2006). Intergenerational residential proximity; a European comparison. Paper presented at the European Population Conference, Liverpool.

Brewster, K. L., \& Rindfuss, R. (2000). Fertility and women's employment in industrialized nations. Annual Review of Sociology, 26, 271-96.

Chesnais, J. C. (1996). Fertility, family, and social policy, in contemporary Western Europe. Population and Development Review, 22, 729-739.

Chesnais, J. C. (1998). Below-replacement fertility in the European Union (EU-15): Facts and policies, 1960-1997. Review of Population and Social Policy, 7, 83-101.

Cioni, E. (1997). Il sistema di parentela. In M. Barbagli \& C. Saraceno (Eds.), Lo stato delle famiglie in Italia. Bologna: Il Mulino.

Dalla Zuanna, G. (2001). The banquet of Aeolus. A familistic interpretation of Italy's lowest low fertility. Demographic Research, 4, 1-29.

Dalla Zuanna, G., \& Crisafulli, C. (2002). Come interpretare il rialzo di fecondità in Italia negli ultimi anni del XX secolo? Paper presented at the seminar La fecondità italiana, Florence, Italy.

Del Boca, D., \& Pasqua, S. (2005b). Labor supply and fertility in Europe, the US. In T. Boeri, D. Del Boca, \& C. Pissarides (Eds.), Women at work: An economic perspective (pp. 125-153). Oxford University Press.

Del Boca, D., Pasqua, S., \& Pronzato, C. (2005a). Fertility and employment in Italy, France, and the UK. Labour, 19(1), 51-77.

Easterlin, R. (1976). The conflict between aspirations and resources. Population and Development Review, 2, 417-425.

Easterlin, R., \& Crimmins, E. (1991). Private materialism, personal self-fulfillment, family life, and public interest. Public Opinion Quarterly, 55, 499-533.

Engelhardt, H., \& Prskawetz, A. (2004). On the changing correlation between fertility and female employment over space and time. European Journal of Population, 20, 35-62.

Gauthier, A. H. (1996). The state and the family: A comparative analysis of family policies in industrialized countries. Oxford: Clarendon Press.

Kertzer, D. I. (1995). Political-economic and cultural explanations of demographic behavior. In S. Greenhalgh (Ed.), Situating fertility: Anthropology and demographic inquiry (pp. 29-52). Cambridge: Cambridge University Press.

Kertzer, D. I. (1997). The proper role of culture in demographic explanation. In G. Jones, R. Douglas, J. Caldwell, \& R. D’Souza (Eds.), The continuing demographic transition (pp. 137-157). Oxford: Clarendon Press.

Kiernan, K. E. (1998). Parenthood and family life in the United Kingdom. Review of Population and Social Policy, 7, 63-81.

Kögel, T. (2004). Did the association between fertility and female employment within OECD countries really change its sign? Journal of Population Economics, 17, 45-65.

Lesthaeghe, R., \& Surkyn, J. (1998). Cultural dynamics and economic theories of fertility change. Population and Development Review, 14, 1-45.

Livi Bacci, M. (1977). A history of Italian fertility. During the last two centuries. Princeton NJ: Princeton University Press.

Livi Bacci, M. (2001). Too few children and too much family. Daedalus, 130, 139-155. 
Livi Bacci, M., \& Savini, S. (2000). Trop de famille et trop peu d'enfants : la fécondité en Italie depuis 1960. Cahiers québécois de démographie, 29, 231-254.

Macunovich, D. J. (1997). A conversation with Richard Easterlin. Journal of Population Economics, 10, $119-136$.

Mason, K. (1997). Gender and demographic change: What do we know? In G. Jones, R. Douglas, J. Caldwell, \& R. D’Souza (Eds.), The continuing demographic transition (pp. 158-177). Oxford: Clarendon Press.

McDonald, P. (2000). Gender equity in theories of fertility transition. Population and Development Review, 26, 427-439.

McDonald, P. (2001). Theory pertaining to low fertility. International perspectives on low fertility: Trends, theories and policies. Paper presented to the IUSSP conference, International Perspectives on Low Fertility, Tokyo.

Mincer, J. (1963). Market prices, opportunity costs, and income effects. In C. F. Christ, et al. (Eds.), Measurement in economics: Studies in mathematical economics and econometrics. Stanford: Stanford University Press.

Morgan, S. P. (2003). Is low fertility a twenty-first-century demographic crisis? Demography, 40, 589-604.

Rindfuss, R. R., Guzzo, K., \& Morgan, S. P. (2003). The changing institutional context of low fertility. Population Research and Policy Review, 22, 411-438.

Sabbadini, L. (1999). La permanenza dei giovani nella famiglia di origine. Modelli di formazione e organizzazione della famiglia. Paper presented to the conference Le famiglie interrogano le politiche sociali, Bologna.

van de Kaa, D. J. (1987). Europe's second demographic transition. Population Bulletin, 42, 1-57. 